\title{
Impaired Insulin-induced Sympathetic Neural Activation and Vasodilation in Skeletal Muscle in Obese Humans
}

\author{
Peter Vollenweider, ${ }^{*}$ Denis Randin, ${ }^{*}$ Luc Tappy, ${ }^{*}$ Eric Jéquier, ${ }^{\star}$ Pascal Nicod, ${ }^{*}$ and Urs Scherrer ${ }^{*}$ \\ *Department of Internal Medicine B, Centre Hospitalier Universitaire Vaudois, 1011 Lausanne, Switzerland; and ${ }^{\ddagger}$ Institute of Physiology, \\ University of Lausanne, 1005 Lausanne, Switzerland
}

\begin{abstract}
The sympathetic nervous system is an important regulatory mechanism of both metabolic and cardiovascular function, and altered sympathetic activity may play a role in the etiology and/or complications of obesity. In lean subjects, insulin evokes sympathetic activation and vasodilation in skeletal muscle. In obese subjects such vasodilation is impaired and, in turn, may contribute to insulin resistance. To examine the relationship between sympathetic and vasodilatory responses in skeletal muscle to hyperinsulinemia, we simultaneously measured muscle sympathetic nerve activity (MSNA) and calf blood flow at basal and during a 2 -h hyperinsulinemic $(6 \mathrm{pmol} / \mathrm{kg}$ per min) euglycemic clamp in eight lean and eight obese subjects. The major findings of this study are twofold: obese subjects had a 2.2 times higher fasting rate of MSNA, and euglycemic hyperinsulinemia, which more than doubled MSNA and increased calf blood flow by roughly $30 \%$ in lean subjects, had only a minor vasodilatory and sympathoexcitatory effect in obese subjects. In contrast, two non-insulin-sympathetic stimuli evoked comparably large increases in MSNA in lean and obese subjects. We conclude that insulin resistance in obese subjects is associated with increased fasting MSNA and a specific impairment of sympathetic neural responsiveness to physiological hyperinsulinemia in skeletal muscle tissue. (J. Clin. Invest. 1994. 93:2365-2371.) Key words: microneurography • hyperinsulinemic euglycemic clamp • insulin resistance • energy expenditure $\bullet$ muscle blood flow
\end{abstract}

\section{Introduction}

The sympathetic nervous system is an important regulatory mechanism of both metabolic and cardiovascular function, and evidence has been provided that sympathetic activity may be altered in animal models of obesity $(1,2)$. Resistance to

Address correspondence to Dr. Urs Scherrer, Department of Internal Medicine B, BH 10.642, CHUV, 1011 Lausanne, Switzerland.

Portions of this work were presented at the 53rd Annual Meeting and Scientific Sessions of the American Diabetes Association in Las Vegas, NV on 12-15 June 1993, and the 47th Annual Fall Conference and Scientific Sessions of the Council for High Blood Pressure Research in San Francisco, CA on 29 September-1 October 1993.

Portions of this work have appeared in abstract form (1993. Diabetes. 42:132a) (1993. Hypertension [Dallas]. 22:451a).

Received for publication 29 November 1993 and in revised form 4 February 1994.

J. Clin. Invest

(c) The American Society for Clinical Investigation, Inc.

$0021-9738 / 94 / 06 / 2365 / 07 \$ 2.00$

Volume 93, June 1994, 2365-2371 insulin-mediated glucose disposal in skeletal muscle is a hallmark of obesity (3-5), and there is abundant evidence indicating that such resistance is taking place, at least in part, at the level of insulin-sensitive cells (3-7). More recently, evidence has accumulated, suggesting that mechanisms proximal to insulin-stimulated cellular glucose uptake, and possibly related to altered vascular function, also may contribute to insulin resistance (8-10). For example, in dogs, transcapillary transport of insulin from plasma to interstitium is rate limiting for insulin-mediated glucose uptake (8), and, using the microdialysis technique, such evidence has also been provided in humans (11). In lean humans, Laakso et al. (10) found that insulin-induced stimulation of muscle blood flow may be an important determinant of insulin-mediated glucose uptake in skeletal muscle tissue. In obese insulin-resistant subjects, insulin loses its ability to stimulate muscle blood flow, a defect that has been proposed to contribute to decreased skeletal muscle glucose uptake (10). However, the underlying mechanisms leading to such an impairment of insulin-induced stimulation of muscle blood flow remain unknown.

In lean healthy subjects, insulin-induced stimulation of muscle blood flow consistently is accompanied by a marked stimulation of sympathetic neural outflow to the same vascular bed (12-14). Such sympathetic activation may modulate muscle blood flow in two ways. First, this sympathetic activity is thought to be at least in part sympathetic vasoconstrictor because it is accompanied by stimulation of norepinephrine release (15). Alternatively, such sympathetic activation, by stimulation of neural sympathetic vasodilator mechanisms, could contribute to vasodilation in skeletal muscle. Data in experimental animals regarding effects of insulin resistance and obesity on insulin-induced sympathetic responses are conflicting. For example, in insulin-resistant rats, there is evidence that sympathetic nerve responses to insulin are markedly augmented (16). On the other hand, in models of genetically inherited obesity in rodents, diet-induced sympathetic responsiveness is impaired (17). Thus, while there is considerable evidence in experimental animals that obesity may alter sympathetic nerve responses to acute hyperinsulinemia, this evidence is conflicting, and no data exist in humans. We therefore directly measured sympathetic nerve discharge to skeletal muscle and its relationship to calf blood flow in insulin-resistant obese subjects and in lean, healthy volunteers during insulin/glucose infusion (euglycemic hyperinsulinemic glucose clamp). To provide further insight into this relationship, we then examined dose-response curves of muscle sympathetic nerve activity (MSNA $)^{1}$ and calf blood flow in lean subjects to insulin/glucose infusion performed at different rates.

1. Abbreviation used in this paper: MSNA, muscle sympathetic nerve activity. 


\section{Methods}

\section{Subjects}

Eight obese subjects (weight $93.8 \pm 6.0 \mathrm{~kg}$, height $166 \pm 4 \mathrm{~cm}$, body mass index $33.8 \pm 1.6 \mathrm{~kg} / \mathrm{m}^{2}$, age $38 \pm 3 \mathrm{yr}$, mean $\pm \mathrm{SE}$ ) and eight age- and sex-matched lean, healthy subjects (weight $63.5 \pm 4.2 \mathrm{~kg}$, height $168 \pm 5$ $\mathrm{cm}$, body mass index $22.2 \pm 0.7 \mathrm{~kg} / \mathrm{m}^{2}$, age $37 \pm 3 \mathrm{yr}$ ) participated in this study after providing informed written consent. All subjects were normotensive, had normal glucose tolerance, were taking no medication, and had no evidence of metabolic or cardiovascular disease at the time of the study. All tests were conducted in the morning after an overnight fast. Subjects had been on a weight maintaining diet containing at least $40 \%$ energy as carbohydrates for $3 \mathrm{~d}$ before the tests. The experimental protocol was approved by the Institutional Review Board on Human Investigation.

\section{General procedures}

Subjects were studied in the supine position. Heart rate (electrocardiogram), respiratory excursions (pneumobelt), blood pressure (Finapres blood pressure monitor; Ohmeda, Englewood, CO) (18), calf blood flow (venous occlusion plethysmography) (19), and efferent MSNA were recorded continuously on an electrostatic recorder and on a tape recorder (R71; TEAC, Corp., Tokyo, Japan). Respiratory excursions were monitored to detect inadvertent performance of a Valsalva maneuver or prolonged expiration; these respiratory maneuvers can markedly stimulate MSNA (20). Intravenous catheters were inserted in a right and a left antecubital vein, one for substrate infusion and the other for blood sampling. Urine was collected before and at the end of the study for nitrogen determination.

\section{Experimental protocols}

Protocol 1: hyperinsulinemic euglycemic clamp. After instrumentation and $1 \mathrm{~h}$ of baseline measurements, all subjects received a primed continuous infusion of crystalline insulin (Actrapid HM; Novo Industri S/A, Bagsvaerd, Denmark) at a rate of $1 \mathrm{mU} / \mathrm{kg}$ per min $(6 \mathrm{pmol} / \mathrm{kg}$ per $\min$ ) for $2 \mathrm{~h}$. Euglycemia was maintained by determining plasma glucose concentration every $5 \mathrm{~min}$ and periodically adjusting a variable infusion of $20 \%$ dextrose (21). Hypokalemia was prevented by administration of $\mathrm{KCl}$ infused at a rate of $4 \mathrm{mmol} / \mathrm{h}$. Hemodynamic measurements and sympathetic nerve activity were recorded for 5 out of every $15 \mathrm{~min}$ throughout the study. Blood samples were collected in the basal state and at timed intervals throughout the study for analysis of substrate and hormone concentrations.

To assess sympathetic responsiveness to noninsulin stimuli, we used baroreceptor deactivation evoked by the Valsalva maneuver (20) and stimulation of cutaneous afferents by 2-min immersion of the hand in ice water (cold pressor test) (22).

Protocol 2: low dose hyperinsulinemic euglycemic clamps in lean subjects. To provide further insight into the relationship between sympathetic and vasodilatory responses, we examined dose-response curves of MSNA and calf blood flow in lean subjects to insulin glucose infusion performed at two different rates. Five of the lean subjects (weight $65.5 \pm 4.6 \mathrm{~kg}$, height $168 \pm 4 \mathrm{~cm}$, body mass index $22.7 \pm 0.9$ $\mathrm{kg} / \mathrm{m}^{2}$, age $35 \pm 4 \mathrm{yr}$ ) participated in these studies. The protocol was the same as above, except that insulin was infused at a rate of $0.5 \mathrm{mU} / \mathrm{kg}$ per min for $2 \mathrm{~h}$ on one occasion and at a rate of $0.15 \mathrm{mU} / \mathrm{kg}$ per min for $2 \mathrm{~h}$ on another occasion.

\section{Recording of sympathetic nerve activity}

Multiunit recordings of sympathetic nerve activity were obtained with unipolar tungsten microelectrodes inserted selectively into muscle nerve fascicles of the peroneal nerve posterior to the fibular head by the microneurographic technique of Vallbo et al. (23). The neural signals were amplified ( by $20-50 \times 10^{3}$ ), filtered ( band width $700-2,000 \mathrm{~Hz}$ ), rectified, and integrated (time constant $0.1 \mathrm{~s}$ ) to obtain a mean voltage display of sympathetic activity. A recording of MSNA was considered acceptable when it revealed spontaneous, pulse-synchronous bursts of neural activity that increased during the Valsalva maneuver, but not during arousal stimuli such as loud noise. For analysis, filtered and mean voltage neurograms were inspected visually on hard copy to identify bursts of sympathetic nerve discharge. Nerve recordings were analyzed with the investigator blinded to group and insulin dose assignment of the subject. In our laboratory, the intraobserver and interobserver coefficients of variation of the mean in identifying bursts are $<6 \%$ and $<9 \%$, respectively (14). Nerve traffic was expressed both as bursts per minute, an index of the frequency of the activity, and as bursts per minute times mean burst amplitude, an index of integrated (total) activity.

\section{Calf blood flow}

Blood flow in the calf was measured with venous occlusion plethysmography, using mercury-in-silastic strain gauges (19). The calf was elevated $10-15 \mathrm{~cm}$ above the level of the right atrium to collapse the veins. The circulation to the foot was arrested by inflating a cuff around the ankles during blood flow determinations, which were performed at 15 -s intervals for $5 \mathrm{~min}$.

\section{Indirect calorimetry}

Energy expenditure and substrate utilization were calculated from respiratory gas exchanges (determined by a computerized, flow-through canopy gas analyzer system [Deltatrac; Datex, Helsinki, Finland]) and urinary nitrogen excretion, after correction for changes in the body urea nitrogen pool as described earlier (14). Total glucose uptake was assumed to be equal to exogenous glucose infusion. The rate of nonoxidative glucose disposal was calculated by subtracting the rate of glucose oxidation from the rate of steady state glucose uptake.

\section{Analytical methods}

Plasma glucose was determined in duplicate by the glucose oxidase method on a glucose analyzer (Beckman Instruments, Inc., Fullerton, CA). Plasma insulin was measured by radioimmunoassay (24), catecholamines by HPLC (25), blood urea nitrogen using a urea analyzer (Beckman Instruments, Inc.), plasma free fatty acid concentrations by a colorimetric method using a kit from Wako (Freiburg, Germany), and urinary nitrogen by the Kjehldahl method.

\section{Data analysis}

Mean arterial pressure was calculated as diastolic pressure plus onethird pulse pressure. Vascular resistance in the calf was calculated as mean arterial pressure in millimeters of mercury divided by blood flow in milliliters per minute per $100 \mathrm{ml}$ tissue and expressed in units.

The $5 \mathrm{~min}$ of data from intraneural recordings of MSNA, calf blood flow, blood pressure, and heart rate collected every $15 \mathrm{~min}$ were averaged to a single value. Whole body glucose uptake, energy expenditure, and substrate oxidation were averaged for 30 -min periods. Statistical analysis was performed using ANOVA for repeated measures and paired $t$ tests with the Bonferroni adjustment for multiple comparisons. Unpaired $t$ tests were used to compare lean with obese subjects. Correlation coefficients were calculated according to the method of least squares. A $P$ value $<0.05$ was considered statistically significant. Data are given as mean $\pm \mathrm{SE}$.

\section{Results}

Plasma glucose and insulin. Plasma glucose concentrations during the basal period were comparable in both groups, whereas plasma insulin concentrations as expected were significantly higher in obese than in lean subjects (Table I). During the hyperinsulinemic euglycemic clamp, the coefficients of variation in plasma glucose concentration were comparable in obese and lean subjects: 4.3 and $4.0 \%$, respectively. During the euglycemic hyperinsulinemic clamp, plasma insulin concentrations increased to significantly higher concentrations $(P$ $<0.05)$ in obese than in lean subjects $(643 \pm 47$ vs $449 \pm 48$ $\mathrm{pmol} /$ liter, by the end of the second hour of infusion ). 


\begin{tabular}{|c|c|c|c|c|c|c|}
\hline & \multicolumn{3}{|c|}{ Lean subjects } & \multicolumn{3}{|c|}{ Obese subjects } \\
\hline & \multirow[b]{2}{*}{ Basal } & \multicolumn{2}{|c|}{$\begin{array}{l}\text { Insulin infusion } \\
\text { (1 mU/kg per min) }\end{array}$} & \multirow[b]{2}{*}{ Basal } & \multicolumn{2}{|c|}{$\begin{array}{c}\text { Insulin infusion } \\
\text { (1 mU/kg per min })\end{array}$} \\
\hline & & $60 \mathrm{~min}$ & $120 \mathrm{~min}$ & & $60 \mathrm{~min}$ & $120 \mathrm{~min}$ \\
\hline Heart rate (beats/min) & $66 \pm 3$ & $69 \pm 4^{*}$ & $70 \pm 3^{*}$ & $67 \pm 4$ & $72 \pm 4^{*}$ & $74 \pm 4^{*}$ \\
\hline \multicolumn{7}{|l|}{ Blood pressure $(\mathrm{mmHg})$} \\
\hline systolic & $135 \pm 6$ & $138 \pm 6$ & $141 \pm 5$ & $141 \pm 3$ & $144 \pm 2$ & $150 \pm 3^{*}$ \\
\hline diastolic & $80 \pm 4$ & $83 \pm 3$ & $82 \pm 3$ & $79 \pm 2$ & $80 \pm 1$ & $81 \pm 2$ \\
\hline mean & $99 \pm 4$ & $101 \pm 4$ & $101 \pm 4$ & $99 \pm 2$ & $102 \pm 1$ & $103 \pm 2$ \\
\hline MSNA (burst/min) & $17 \pm 3^{\ddagger}$ & $28 \pm 6^{*}$ & $32 \pm 5^{*}$ & $37 \pm 5$ & $39 \pm 6$ & $41 \pm 5^{*}$ \\
\hline$(U)^{\S}$ & $217 \pm 38^{\ddagger}$ & $364 \pm 80^{* \neq}$ & $618 \pm 136^{*}$ & $486 \pm 63$ & $587 \pm 103^{*}$ & $586 \pm 98^{*}$ \\
\hline Calf blood flow $(\mathrm{ml} / 100 \mathrm{ml}$ per min $)$ & $2.0 \pm 0.2$ & $2.5 \pm 0.3^{* \pm}$ & $2.5 \pm 0.3^{* \neq}$ & $1.6 \pm 0.1$ & $1.6 \pm 0.1$ & $1.7 \pm 0.1^{*}$ \\
\hline Calf vascular resistance $(U)$ & $55 \pm 8^{\ddagger}$ & $40 \pm 8^{* \pm}$ & $40 \pm 7^{* \pm}$ & $66 \pm 5$ & $67 \pm 5$ & $64 \pm 5$ \\
\hline Glucose (mmol/liter) & $5.4 \pm 0.2$ & $5.0 \pm 0.2^{\ddagger}$ & $5.1 \pm 0.1$ & $5.7 \pm 0.2$ & $5.6 \pm 0.1$ & $5.3 \pm 0.1^{*}$ \\
\hline Insulin (pmol/liter) & $48 \pm 6^{\ddagger}$ & $433 \pm 44^{* \pm}$ & $449 \pm 48^{* \ddagger}$ & $103 \pm 9$ & $688 \pm 60^{*}$ & $643 \pm 47^{*}$ \\
\hline Norepinephrine (nmol/liter) & $1.35 \pm 0.15$ & $2.10 \pm 0.34^{*}$ & $2.05 \pm 0.34^{*}$ & $1.59 \pm 0.21$ & $2.06 \pm 0.26^{*}$ & $2.11 \pm 0.27^{*}$ \\
\hline
\end{tabular}

Entries are mean \pm SE for eight subjects in each group. Hemodynamic and MSNA measurements represent the average value of three 5-min periods of basal and the average of the last $5 \mathrm{~min}$ of the first and second hour of infusion. ${ }^{\S}$ MSNA given in $\mathrm{U}$ (bursts/min $\cdot \mathrm{mean}$ burst amplitude); ${ }^{*} P<0.05$ vs corresponding basal period; ${ }^{\ddagger} P<0.05$ lean vs obese subjects.

$M S N A$, calf blood flow, and calf vascular resistance. At basal, obese subjects had a significantly higher rate of sympathetic firing than lean subjects ( $37 \pm 5$ vs $17 \pm 3$ bursts/min). In lean subjects, the 2-h euglycemic hyperinsulinemic clamp markedly stimulated both MSNA and calf blood flow; it increased MSNA burst frequency by $94 \pm 10 \%$ and calf blood flow by $29 \pm 5 \%$, whereas it decreased calf vascular resistance by $20 \pm 3 \%$ (Table I, Figs. 1 and 2). In contrast, in obese subjects, even though $2 \mathrm{~h}$ of insulin/glucose infusion increased plasma insulin concentrations to significantly higher levels, it evoked markedly smaller increases in MSNA burst frequency $(9 \pm 3 \%, P$ $<0.05$ vs lean) and had no detectable effect on calf blood flow and calf vascular resistance (Table I, Figs. 1 and 2). The former finding is not caused by a nonspecific impairment of sympathetic outflow by obesity, since noninsulin stimuli to sympathetic outflow evoked comparably large increases in MSNA burst frequency in obese and lean subjects. Peak sympathetic burst frequencies in obese and lean were $71 \pm 8$ and $67 \pm 4$ bursts /min, respectively $(P>0.1$, obese vs lean $)$, during a Valsalva maneuver; during a cold pressor test, peak MSNA responses were $54 \pm 6$ and $45 \pm 3$ bursts/min, respectively ( $P$ $>0.1$ ).

When the data of all 16 subjects included in this study were analyzed, there was a direct correlation between fasting insulin-

\section{8 y BMl: $21 \mathrm{~kg} / \mathrm{m} 2$}

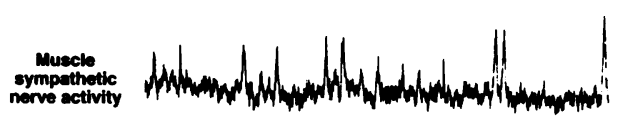

Calf blood flow
(mVimin'100ml)

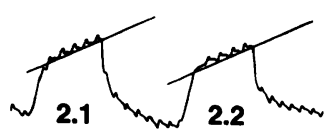

Plasma insulin

(pmolin)

31 y

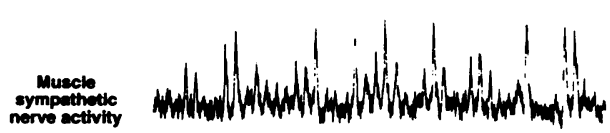

Calf blood flow
( $\mathrm{m} / \mathrm{min} / 100 \mathrm{ml})$

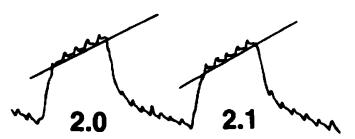

78

Basal
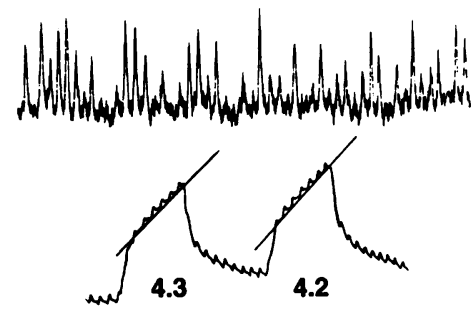

301

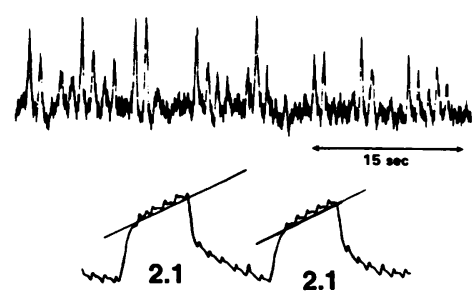

493

Insulin/glucose infusion
Figure 1. Segments of simultaneous recordings of MSNA and calf blood flow in a lean (top) and an obese (bottom) subject obtained at basal and during the last $5 \mathrm{~min}$ of a 2-h insulin infusion (euglycemic clamp). On these mean voltage displays of MSNA, each peak represents a spontaneous burst of sympathetic discharge. Even though in this obese subject insulin glucose infusion resulted in plasma insulin concentrations that were higher than those observed in this lean subject, they did not have any detectable stimulatory effect on sympathetic nerve activity or blood flow in skeletal muscle. 

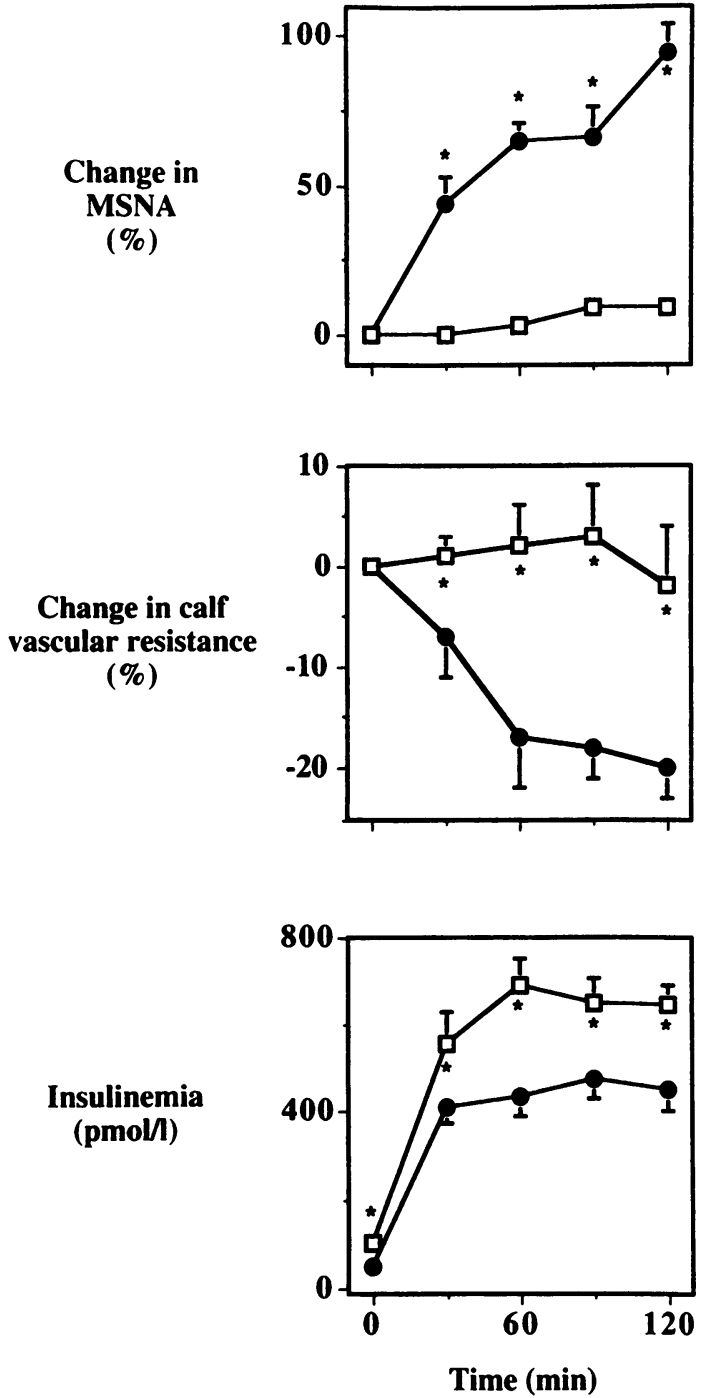

Figure 2. Line graphs showing the effects on plasma insulin concentration, calf vascular resistance, and MSNA of a 2-h insulin infusion ( $1 \mathrm{mU} / \mathrm{kg}$ per min, euglycemic hyperinsulinemic clamp) in lean $(\bullet-\bullet)$ and obese $(\square-\square)$ subjects. Data represent mean \pm SE for eight subjects in each group. ${ }^{*} P<0.05$ lean vs obese subjects. Even though insulin infusion in obese subjects increased plasma insulin concentrations to significantly higher levels than in lean subjects, such hyperinsulinemia did not have any detectable effect on either MSNA or calf vascular resistance.

emia and fasting MSNA burst frequency $(r=0.56, P<0.03)$, whereas fasting MSNA burst frequency and glucose uptake during the last $30 \mathrm{~min}$ of insulin/glucose infusion were inversely related $(r=0.68, P<0.004)$.

Plasma norepinephrine and potassium. In both lean and obese subjects, plasma norepinephrine had increased signifcantly $(P<0.05)$ by the end of the 2 -h euglycemic hyperinsulinemic clamp (Table I).

Serum potassium remained within the normal range in both groups. Plasma potassium concentrations at the end of the 2-h infusions of insulin/glucose were 3.6 \pm 0.1 in lean and $3.6 \pm 0.1 \mathrm{mmol} /$ liter in obese subjects.

Blood pressure and heart rate. In both groups, blood pressure increased slightly during insulin/glucose infusion; in lean subjects this increase $(2 \pm 2 \mathrm{mmHg})$ in mean arterial pressure was not statistically significant, whereas in obese subjects this increase $(4 \pm 1 \mathrm{mmHg})$ did reach statistical significance $(P$ $<0.05$ ). Heart rate increased significantly in both study groups (Table I).

Carbohydrate metabolism and energy expenditure. Insulin infusion at the same rate resulted in markedly smaller stimulation of total glucose uptake, carbohydrate oxidation, and nonoxidative glucose disposal in obese than in lean subjects (Table II).

\section{Low dose insulin infusion studies in lean subjects (protocol 2)}

MSNA, calf blood flow, and calf vascular resistance. Insulin/ glucose infusion, which increased plasma insulin concentrations roughly 2.5-, 5-, and 9-fold, evoked increases in MSNA and muscle blood flow and decreases in calf vascular resistance that were comparable (Table III, Fig. 3).

Heart rate and arterial pressure. Similar to MSNA and calf blood flow, all three rates of insulin infusion also had a comparable chronotropic effect (Table III). Blood pressure remained unchanged during all three protocols.

Carbohydrate metabolism. Values for glucose uptake during the last $30 \mathrm{~min}$ of insulin infusion at a rate of $1,0.5$, and $0.15 \mathrm{mU} / \mathrm{kg}$ per min were $36 \pm 4,26 \pm 3$, and $12 \pm 1 \mu \mathrm{mol} / \mathrm{kg}$ per min, respectively.

\section{Discussion}

There is increasing evidence that an impairment in insulin-induced stimulation of muscle blood flow may represent one important mechanism contributing to insulin resistance in obese humans (10). However, the underlying mechanisms that may lead to such an impairment are incompletely understood. More specifically, little is known about the relationship between insulin-induced sympathetic activation and vasodilation in skeletal muscle during euglycemic hyperinsulinemia. The ability to perform simultaneous measurements of sympathetic neural outflow and blood flow to skeletal muscle tissue allowed us to directly examine this issue. The principal new findings are that $(a)$ obese subjects had higher rates of sympathetic nerve discharge to skeletal muscle than lean subjects; $(b)$ euglycemic hyperinsulinemia at high physiological concentrations, which in lean subjects consistently evoked marked increases in both calf blood flow and muscle sympathetic nerve discharge, had only minor vasodilatory and sympathoexcitatory effects in obese insulin-resistant subjects; and $(c)$ low dose insulin infusion in lean subjects, which increased plasma insulin concentrations to levels similar to those observed in fasting obese subjects, elicited sympathetic and vasodilatory effects in skeletal muscle tissue that were similar to those evoked by high physiologic hyperinsulinemia. These findings indicate that in humans insulin resistance is associated with increased fasting MSNA and an impairment of sympathetic neural and vasodilatory responsiveness to high physiological hyperinsulinemia in skeletal muscle, a major insulin-sensitive tissue. Moreover, these findings provide evidence that the impairment in insulin-induced vasodilation in obese subjects is not related to exaggerated insulin-induced stimulation of sympathetic vasoconstrictor outflow.

The present data represent the first demonstration in humans that not only insulin-induced stimulation of blood flow but also insulin-induced stimulation of sympathetic neural outflow to skeletal muscle tissue are impaired in obese subjects. 


\begin{tabular}{|c|c|c|c|c|c|c|}
\hline & \multicolumn{3}{|c|}{ Lean subjects } & \multicolumn{3}{|c|}{ Obese subjects } \\
\hline & \multirow[b]{2}{*}{ Basal } & \multicolumn{2}{|c|}{$\begin{array}{l}\text { Insulin infusion } \\
\text { (1 mU/kg per min) }\end{array}$} & \multirow[b]{2}{*}{ Basal } & \multicolumn{2}{|c|}{$\begin{array}{l}\text { Insulin infusion } \\
\text { (1 mU/kg per min) }\end{array}$} \\
\hline & & $30-60 \mathrm{~min}$ & $90-120 \mathrm{~min}$ & & $30-60 \mathrm{~min}$ & $90-120 \mathrm{~min}$ \\
\hline \multicolumn{7}{|l|}{ Energy expenditure } \\
\hline$(\mathrm{kcal} / \mathrm{min})$ & $0.93 \pm 0.06$ & $1.01 \pm 0.07^{*}$ & $1.01 \pm 0.07^{*}$ & $1.12 \pm 0.05^{* \pm}$ & $1.20 \pm 0.05^{* \pm}$ & $1.19 \pm 0.05^{*}$ \\
\hline$(k J / \min )$ & $3.92 \pm 0.25$ & $4.21 \pm 0.29^{*}$ & $4.33 \pm 0.29 *$ & $4.69 \pm 0.21$ & $5.03 \pm 0.20^{*}$ & $5.00 \pm 0.20^{*}$ \\
\hline \multicolumn{7}{|l|}{ Carbohydrate oxidation } \\
\hline (mg/kg per min) & $1.30 \pm 0.22$ & $2.74 \pm 0.28^{*}$ & $3.16 \pm 0.32^{*}$ & $1.07 \pm 0.22$ & $2.17 \pm 0.37^{*}$ & $2.21 \pm 0.36^{*}$ \\
\hline ( $\mu \mathrm{mol} / \mathrm{kg}$ per min) & $7 \pm 1$ & $15 \pm 2^{*}$ & $18 \pm 2^{*}$ & $6 \pm 1$ & $10 \pm 2^{*}$ & $12 \pm 2 *$ \\
\hline \multicolumn{7}{|l|}{ Total glucose uptake } \\
\hline (mg/kg per min) & - & $6.17 \pm 0.82^{*}$ & $7.18 \pm 0.52^{*}$ & - & $3.39 \pm 38^{* \neq}$ & $3.50 \pm 0.42^{* \pm}$ \\
\hline$(\mu \mathrm{mol} / \mathrm{kg}$ per min $)$ & - & $34 \pm 5^{*}$ & $40 \pm 3$ & - & $18 \pm 2^{* \neq}$ & $19 \pm 2^{* \pm}$ \\
\hline \multicolumn{7}{|c|}{ Nonoxidative glucose disposal } \\
\hline (mg/kg per min) & - & $3.43 \pm 0.66^{*}$ & $4.03 \pm 0.63^{*}$ & - & $1.22 \pm 0.36^{* \neq}$ & $1.29 \pm 0.34^{* \pm}$ \\
\hline ( $\mu \mathrm{mol} / \mathrm{kg}$ per min) & - & $19 \pm 4^{*}$ & $22 \pm 4^{*}$ & - & $7 \pm 2^{* \pm}$ & $7 \pm 2^{* \ddagger}$ \\
\hline
\end{tabular}

Entries are mean $\pm S E$ for eight subjects in each group. Substrate oxidation measurements represent the average value of the last 30 min of basal and the average of the last $30 \mathrm{~min}$ of the first and second hour of infusion. ${ }^{*} P<0.05$ vs corresponding basal period. ${ }^{\ddagger} P<0.05$ lean vs obese subjects.

This finding is not related to a nonspecific impairment of sympathetic responsiveness in overweight subjects because reflex sympathetic responses during a Valsalva maneuver and during immersion of the hand in ice water were preserved, indicating that in obese subjects efferent sympathetic pathways could respond appropriately to baroreceptor deactivation and stimulation of cutaneous afferents. This finding is also unlikely to be related to differences between the two groups in plasma insulin concentrations, the main stimulus of sympathetic outflow and blood flow during insulin/glucose infusion (14). Indeed, even though plasma insulin concentrations in obese subjects were significantly higher both at the end of the first and of the second hour of insulin infusion, they barely had any sympathoexcitatory (and vasodilatory) effect in skeletal muscle. Finally, the impaired sympathetic and vasodilatory responsiveness in obese subjects cannot be explained on the basis of resistance to insulin stimulation of glucose uptake alone, because attenuated stimulation of glucose uptake during low dose insulin infusion in lean subjects did not result in attenuated stimulation of MSNA and calf blood flow.

We therefore considered an alternative possibility to explain the impaired sympathetic responsiveness to acute eugly-

Table III. Responses to 2-h Insulin Infusion Performed at Different Rates in Lean Subjects

\begin{tabular}{|c|c|c|c|c|c|c|c|c|c|}
\hline & \multirow[b]{2}{*}{ Basal } & \multicolumn{2}{|c|}{$\begin{array}{l}\text { Insulin infusion } \\
\text { (1 mU/kg per min) }\end{array}$} & \multirow[b]{2}{*}{ Basal } & \multicolumn{2}{|c|}{$\begin{array}{c}\text { Insulin infusion } \\
(0.5 \mathrm{mU} / \mathrm{kg} \text { per } \mathrm{min})\end{array}$} & \multirow[b]{2}{*}{ Basal } & \multicolumn{2}{|c|}{$\begin{array}{c}\text { Insulin infusion } \\
(0.15 \mathrm{mU} / \mathrm{kg} \text { per min }) \\
\end{array}$} \\
\hline & & $60 \mathrm{~min}$ & $120 \mathrm{~min}$ & & $60 \mathrm{~min}$ & $120 \mathrm{~min}$ & & $60 \mathrm{~min}$ & $120 \mathrm{~min}$ \\
\hline $\begin{array}{l}\text { Heart rate } \\
\quad(\text { beats } / \text { min }) \\
\text { Mean arterial } \\
\text { pressure }\end{array}$ & $63 \pm 3$ & $66 \pm 4$ & $70 \pm 4^{*}$ & $63 \pm 2$ & $67 \pm 4$ & $71 \pm 8^{*}$ & $61 \pm 4$ & $67 \pm 4^{*}$ & $66 \pm 3^{*}$ \\
\hline $\begin{array}{l}(m m H g) \\
\text { MSNA }\end{array}$ & $96 \pm 4$ & $98 \pm 5$ & $97 \pm 4$ & $95 \pm 6$ & $97 \pm 6$ & $97 \pm 4$ & $92 \pm 3$ & $95 \pm 4$ & $96 \pm 3$ \\
\hline $\begin{array}{l}\text { (bursts/min) } \\
(U)^{\ddagger} \\
\text { Calf blood flow }\end{array}$ & $\begin{array}{c}18 \pm 2 \\
212 \pm 12\end{array}$ & $\begin{array}{c}25 \pm 4^{*} \\
322 \pm 31^{*}\end{array}$ & $\begin{array}{c}31 \pm 4^{*} \\
402 \pm 52^{*}\end{array}$ & $\begin{array}{c}20 \pm 4 \\
219 \pm 11\end{array}$ & $\begin{array}{c}28 \pm 5^{*} \\
354 \pm 27^{*}\end{array}$ & $\begin{array}{c}32 \pm 6^{*} \\
413 \pm 29^{*}\end{array}$ & $\begin{array}{r}15 \pm 3 \\
179 \pm 6\end{array}$ & $\begin{array}{c}21 \pm 3 \\
268 \pm 30^{*}\end{array}$ & $\begin{array}{c}28 \pm 3^{*} \\
376 \pm 43^{*}\end{array}$ \\
\hline $\begin{array}{l}(\mathrm{ml} / 100 \mathrm{ml} \mathrm{per} \mathrm{min}) \\
\text { Calf vascular }\end{array}$ & $1.9 \pm 0.2$ & $2.1 \pm 0.3$ & $2.4 \pm 0.3^{*}$ & $1.5 \pm 0.1$ & $1.8 \pm 0.1^{*}$ & $2.0 \pm 0.1^{*}$ & $1.3 \pm 0.1$ & $1.6 \pm 0.1^{*}$ & $1.6 \pm 0.1^{*}$ \\
\hline $\begin{array}{l}\text { resistance }(U) \\
\text { Glucose }\end{array}$ & $55.2 \pm 8.4$ & $51.9 \pm 8.9$ & $46.4 \pm 7.8^{*}$ & $66.1 \pm 9.2$ & $53.8 \pm 3.5^{*}$ & $48.6 \pm 3.5^{*}$ & $70.7 \pm 6.3$ & $61.1 \pm 5.2^{*}$ & $61.7 \pm 3.7^{*}$ \\
\hline $\begin{array}{l}\text { (mmol/liter) } \\
\text { Insulin }\end{array}$ & $5.3 \pm 0.2$ & $5.1 \pm 0.3$ & $5.2 \pm 0.1$ & $5.1 \pm 0.2$ & $5.1 \pm 0.2$ & $5.1 \pm 0.1$ & $5.2 \pm 0.1$ & $5.1 \pm 0.1$ & $5.1 \pm 0.1$ \\
\hline $\begin{array}{c}(p m o l / l i t e r) \\
\text { Norepinephrine }\end{array}$ & $49.1 \pm 6.1$ & $411.1 \pm 26.1^{*}$ & $420.7 \pm 33.7^{*}$ & $47.8 \pm 7.8$ & $223.7 \pm 30.2^{* \$}$ & $192.0 \pm 19.0^{* 5}$ & $50.5 \pm 7.3$ & $111.4 \pm 11.1^{\text {* }}$ & $127 \pm 10.3^{* 5}$ \\
\hline (nmol/liter) & $1.42 \pm 0.17$ & $2.24 \pm 0.34^{*}$ & $1.78 \pm 0.24$ & $1.50 \pm 0.30$ & $2.02 \pm 0.63$ & $1.50 \pm 0.36$ & $1.36 \pm 0.19$ & $2.24 \pm 0.34$ & $1.78 \pm 0.24$ \\
\hline
\end{tabular}

Entries are mean \pm SEM for five subjects. Hemodynamic and MSNA measurements represent the average value of three 5-min periods of basal and the average of the last $5 \mathrm{~min}$ of the first and second hour of insulin infusion. ${ }^{\ddagger}$ MSNA given in U (bursts/min $\cdot$ mean burst amplitude). $* P<0.05$ vs corresponding baseline value.

$P<0.05$ vs insulin infusion at a rate of $1 \mathrm{mU} / \mathrm{kg}$ per min. 


\section{Change in MSNA (bursts/min)}

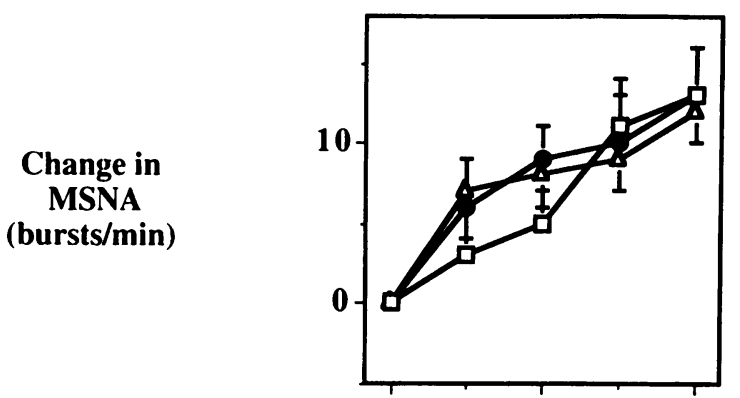

Change in calf
vascular resistance (\%)

\section{Insulinemia (pmol/l)}
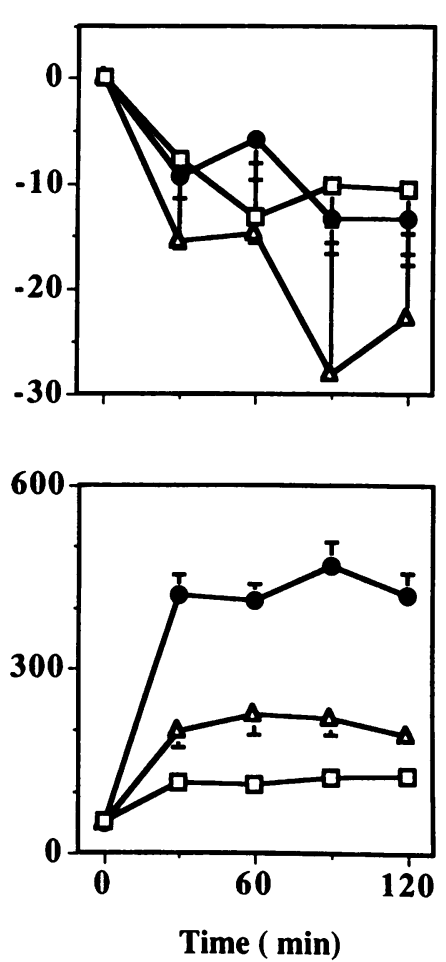

Time ( min)

Figure 3. Line graphs showing effects on plasma insulin concentration and changes in calf vascular resistance and MSNA of 2-h insulin infusions in lean subjects performed at three different rates $(\bullet-\bullet, 1$ $\mathrm{mU} / \mathrm{kg}$ per min; $\triangle \longrightarrow \Delta, 0.5 \mathrm{mU} / \mathrm{kg}$ per min; $\square-\square, 0.15 \mathrm{mU} / \mathrm{kg}$ per min). Data represent mean $\pm S E$ for five subjects. Even though plasma insulin levels observed at the end of highest and the lowest rates of insulin infusion used differed by roughly threefold, they were associated with increases in MSNA and decreases in calf vascular resistance that were comparable.

cemic hyperinsulinemia in obese subjects. We found that obese subjects had markedly higher rates of sympathetic discharge to skeletal muscle at basal than lean subjects, an observation which is in accordance with recent findings from this and another laboratory, suggesting that body fat may be an important determinant of resting sympathetic nerve activity in humans $(26,27)$. Indeed, in the present study, obese subjects had a roughly twofold higher rate of sympathetic nerve discharge at basal than lean subjects, a rate which tended to be still higher than the rate observed in lean subjects at the end of a 2-h insulin/glucose infusion. This observation raises the possibility that such high basal rates of sympathetic nerve discharge in obese subjects may lie close to the maximal increases in MSNA that can be obtained by acute elevation of insulinemia to high physiological concentrations in humans. To test this possibility, we examined effects of low dose insulin/glucose infusion

on sympathetic nerve traffic and calf blood flow in lean subjects. We found that insulin infusion both at a rate six times and two times lower than the one used in the initial experiments markedly stimulated sympathetic activity. Indeed, increases in sympathetic activity were not statistically different during the three experimental conditions. Taken together, these findings are consistent with the interpretation that during our initial experiments (insulin infusion at a rate of $1 \mathrm{mU} / \mathrm{kg}$ per $\min$ ) sympathetic responses to hyperinsulinemia did not fall on the steep slope, but already fell on the upper flat part of the stimulus-response curve relating plasma insulin concentrations to efferent sympathetic discharge to skeletal muscle in lean humans. With regard to obese subjects, two possible interpretations can be considered. The attenuated sympathetic responsiveness to acute hyperinsulinemia in obese subjects may be related to a resistance to insulin's sympathoexcitatory effects and thus may represent another feature of obesity-induced insulin resistance. Alternatively, the high rate of sympathetic discharge at basal in obese subjects, which could possibly be related to chronic hyperinsulinemia, may lie close to the maximal insulin-induced sympathetic activation in skeletal muscle and thus may preclude the demonstration of any further increase during acute elevation of plasma insulin concentrations to high physiological levels. With regard to the former, there is evidence for an impairment in sympathetic responsiveness in genetically obese animal models (17), and recent findings in humans indicate that short-term dexamethasone administration, possibly by interfering with insulin's central neural actions, impairs insulin's ability to stimulate both sympathetic activity and blood flow in skeletal muscle (13). On the other hand, preserved sensitivity to insulin's sympathoexcitatory effects in chronically hyperinsulinemic obese subjects may lead to sustained sympathetic activation and could represent one potential mechanism contributing to the increased incidence of cardiovascular complications in overweight subjects (28).

In lean subjects, sympathetic activation evoked by acute elevation of plasma insulin to high physiological concentrations does not raise blood pressure (12-14), an observation that has been attributed to a balance between insulin's opposing vasodilatory depressor and sympathoexcitatory pressor effects in skeletal muscle. The present finding in obese subjects, of an attenuated insulin-induced sympathetic activation, may offer one potential explanation for the observation that, despite an attenuated insulin-induced depressor effect, insulin infusion had only a minor effect as in the present study or, as reported previously (29), had no effect on arterial pressure.

In contrast to MSNA and calf blood flow, heart rate increased similarly in obese and lean subjects during euglycemic hyperinsulinemia. Such increases in heart rate are thought to be sympathetically mediated because they are abolished by propranolol administration (30). Thus, this finding suggests that in obese subjects attenuation of insulin-induced sympathetic activation may not be generalized. This interpretation would also be consistent with the present observation that during insulin/glucose infusion venous plasma norepinephrine concentrations increased significantly in both lean and obese subjects.

In experimental animal models, there is evidence that insulin resistance may be associated with exaggerated sympathetic activation during euglycemic hyperinsulinemia (16). Similarly, in hypertensive insulin-resistant humans, Lembo et al. (15) recently provided evidence for augmented stimulation of 
norepinephrine release into forearm tissue by insulin. Moreover, there is precedent in humans for the ability of sympathetically induced vasoconstriction to overcome metabolically induced vasodilation in skeletal muscle. For example, in exercising humans, stimulation of sympathetic vasoconstrictor outflow by upright posture has been demonstrated to override metabolically induced vasodilation in contracting skeletal muscle (31). The present findings demonstrate that in obese subjects euglycemic hyperinsulinemia at high physiological concentrations does not have any detectable effect on calf blood flow and calf vascular resistance, a finding which is in accordance with a previous report (10). More importantly, the present observations indicate that this lack of stimulation of muscle blood flow cannot be explained on the basis of an augmented basal and/or insulin-induced stimulation of sympathetic vasoconstrictor outflow. Indeed, in any one of the lean controls, vasodilatory responses at the end of insulin/glucose infusion were markedly greater than those in obese subjects, whereas sympathetic activity was comparable between the two groups.

While the present data demonstrate strikingly different blood flow and MSNA responses to euglycemic hyperinsulinemia in lean and obese subjects, they do not elucidate the underlying mechanism of insulin-induced sympathetic activation and vasodilation. Potential mechanisms by which insulin may exert its sympathoexcitatory and vasodilatory effects include central and peripheral actions. With regard to the former, recent data in rats indicate that anteroventral third ventricle lesions abolish sympathetic neural responses to hyperinsulinemia (32). This concept of a central neural action of insulin is consistent with findings in humans, showing that local intraarterial insulin infusion, in contrast to systemic intravenous infusion, did not have any stimulatory effect on sympathetic activity in skeletal muscle (15). Whether such sympathetic activation, by stimulation of sympathetic neural vasodilator pathways, also contributes to insulin-induced vasodilation in skeletal muscle remains to be determined.

In conclusion, these experimental findings in humans show that obesity is associated with profound alterations in sympathetic nerve activity characterized by increased fasting activity and a specific attenuation of sympathetic responsiveness to hyperinsulinemia.

\section{Acknowledgments}

This work was supported by grants from the Swiss National Science Foundation (32-28668.90 and 32-36280.92), the Emma Muschamp Foundation, the Sandoz Foundation, Nestec SA, Vevey, Switzerland, and the Max Clöetta Foundation.

\section{References}

1. Bray, G. A., D. A. York, and J. Fisler. 1989. Experimental obesity: a homeostatic failure due to defective nutrient stimulation of the sympathetic nervous system. Vitam. Horm. 45:1-125.

2. Young, J. B., and L. Landsberg. 1983. Diminished sympathetic nervous system activity in genetically obese (ob/ob) mouse. Am. J. Physiol. 245:E148E154. 162.

3. Olefsky, J. 1981. Insulin resistance and insulin action. Diabetes. 30:148-

4. Reaven, G. M. 1988. Role of insulin resistance in human disease. Diabetes. 37:1595-1607.

5. Kolterman, O. G., J. Insel, M. Saekow, and J. M. Olefsky. 1980. Mechanisms of insulin resistance in human obesity. Evidence for receptor and postreceptor defects. J. Clin. Invest. 65:1272-1284.
6. Ciaraldi, T. P., O. G. Kolterman, and J. M. Olefsky. 1981. Mechanism of the postreceptor defect in insulin action in human obesity. Decrease in glucose transport system activity. J. Clin. Invest. 68:875-880.

7. Dohm, G. L., E. B. Tapscott, W. J. Pories, D. J. Dabbs, E. G. Flickinger, D. Meelheim, T. Fushiki, S. M. Atkinson, C. W. Elton, and J. F. Caro. 1988. An in vitro human muscle preparation suitable for metabolic studies. Decreased insulin stimulation of glucose transport in muscle from morbidly obese and diabetic subjects. J. Clin. Invest. 82:486-494.

8. Yang, Y. J., I. D. Hope, M. Ader, and R. N. Bergman. 1989. Insulin transport across capillaries is rate limiting for insulin action in dogs. J. Clin. Invest. 84:1620-1628.

9. Laakso, M., S. V. Edelman, G. Brechtel, and A. D. Baron. 1990. Decreased effect of insulin to stimulate muscle blood flow in obese man. A novel mechanism for insulin resistance. J. Clin. Invest. 85:1844-1852.

10. Laakso, M., S. V. Edelman, G. Brechtel, and A. D. Baron. 1990. Impaired insulin-mediated skeletal muscle blood flow in patients with NIDDM. Diabetes. 41:1076-1083.

11. Jansson, P., J. Fowelin, H. Von Schenk, U. Smith, and P. Lönnroth. 1993. Measurement by microdialysis of the insulin concentration in subcutaneous interstitial fluid. Diabetes. 42:1469-1473.

12. Anderson, E. A., R. P. Hoffman, T. W. Balon, C. A. Sinkey, and A. L. Mark. 1991. Hyperinsulinemia produces both sympathetic neural activation and vasodilation in normal humans. J. Clin. Invest. 87:2246-2252.

13. Scherrer, U., P. Vollenweider, D. Randin, E. Jéquier, P. Nicod, and L. Tappy. 1993. Suppression of insulin induced sympathetic activation and vasodilation by dexamethasone in humans. Circulation. 88:388-394.

14. Vollenweider, P., L. Tappy, D. Randin, P. Schneiter, E. Jéquier, P. Nicod, and U. Scherrer. 1993. Differential effects of hyperinsulinemia and carbohydrate metabolism on sympathetic nerve activity and muscle blood flow in humans. $J$. Clin. Invest. 92:147-154.

15. Lembo, G., R. Napoli, B. Capaldo, V. Rendina, G. Iaccarino, M. Volpe, B. Trimarco, and L. Saccá. 1992. Abnormal sympathetic overactivity evoked by insulin in the skeletal muscle of patients with essential hypertension. J. Clin. Invest. 90:24-29.

16. Morgan, D. A., T. W. Balon, and A. L. Mark. 1991. High fructose diet promotes exaggerated sympathetic and pressor responses to hyperinsulinemia in rats. FASEB (Fed. Am. Soc. Exp. Biol.) J. 5:A1497. (Abstr.)

17. Holt, S., D. A. York, and J. T. R. Fitzsimons. 1983. The effect of corticosterone, cold exposure and overfeeding with sucrose on brown adipose tissue of obese Zucker rats (fa/fa). Biochem. J. 214:215-223.

18. Parati, G., R. Casadei, A. Gropelli, M. DiRienzo, and G. Mancia. 1989. Comparison of finger and intra-arterial blood pressure monitoring at rest and during laboratory testing. Hypertension (Dallas). 13:647-655.

19. Greenfield, A. D. M., R. J. Whitney, and J. F. Mowbray. 1963. Methods for the investigation of peripheral blood flow. Br. Med. Bull. 19:101-109.

20. Delius, W., K. E. Hagbarth, A. Hongell, and B. G. Wallin. 1972. Maneuvers affecting sympathetic outflow in human muscle nerves. Acta Physiol. Scand. 84:82-94.

21. DeFronzo, R. A., J. D. Tobin, and R. Andres. 1979. Glucose clamp technique: a method for quantifying insulin secretion and resistance. Am. J. Physiol. 237:E214-E223.

22. Victor, R. G., W. N. Leimbach, D. R. Seals, B. G. Wallin, and A. L. Mark. 1987. Effects of the cold pressure test on muscle sympathetic nerve activity in humans. Hypertension (Dallas). 9:429-436.

23. Vallbo, A. B., K. E. Hagbarth, H. E. Torebjörk, and B. G. Wallin. 1979. Somatosensory, proprioceptive, and sympathetic activity in human peripheral nerves. Physiol. Rev. 59:919-957.

24. Herbert, V., K. S. Lau, C. W. Gottlieb, and S. J. Bleicher. 1965. Coated charcoal immunoassay of insulin. J. Clin. Endocrinol. \& Metab. 25:1375-1384.

25. Hallmann, J., L. O. Farnebo, B. Hamberger, and G. Jonsson. 1978. A sensitive method for determination of plasma catecholamines using liquid chromatography with electrochemical detection. Life Sci. 23:1049-1052.

26. Spraul, M., E. Ravussin, A. M. Fontvieille, R. Rising, D. E. Larson, and E. A. Anderson. 1993. Reduced sympathetic nervous activity. A potential mechanism predisposing to body weight gain. J. Clin. Invest. 92:1730-1735.

27. Randin, D., P. Vollenweider, L. Tappy, E. Jéquier, P. Nicod, and U. Scherrer. 1993. Sustained sympathetic activation in skeletal muscle in overweight humans. Diabetes. 42:94A. (Abstr.)

28. Modan, M., and H. Halkin. 1991. Hyperinsulinemia or increased sympathetic drive as links for obesity and hypertension. Diabetes Care. 14:470-487.

29. Baron, A., and G. Brechtel. 1993. Insulin differentially regulates systemic and skeletal muscle vascular resistance. Am. J. Physiol. 265:E61-E67.

30. Acheson, K., E. Jéquier, and J. Wahren. 1983. Influence of $\beta$-adrenergic blockade on glucose-induced thermogenesis in man. J. Clin. Invest. 72:981-986.

31. Joyner, M. J., R. L. Lennon, D. J. Wedel, S. H. Rose, and J. T. Shepherd. 1990. Blood flow to contracting human muscles: influence of increased sympathetic activity. J. Appl. Physiol. 68:1453-1457.

32. Muntzel, M. S., A. L. Mark, and A. K. Johnson. 1993. Anteroventral third ventricle lesions abolish sympathetic neural responses to hyperinsulinemia. $H y$. pertension (Dallas). 22:420a. (Abstr.) 